\title{
One-year clinical and angiographic results of hybrid coronary revascularization
}

\author{
Ivy S. Modrau, MD, DMSc, ${ }^{a}$ Niels R. Holm, MD, ${ }^{b}$ Michael Mæng, MD, PhD, ${ }^{b}$ \\ Hans E. Bøtker, MD, PhD, DMSc, ${ }^{b}$ Evald H. Christiansen, MD, PhD, ${ }^{b}$ Steen D. Kristensen, MD, DMSc, ${ }^{b}$ \\ Jens F. Lassen, MD, PhD, ${ }^{b}$ Leif Thuesen, MD, DMSc, ${ }^{\mathrm{b}}$ and Per H. Nielsen, MD, ${ }^{\mathrm{a}}$ on behalf of the Hybrid \\ Coronary Revascularization Study Group
}

\begin{abstract}
Objective: To evaluate 1-year clinical and angiographic results after hybrid coronary revascularization (HCR) combining off-pump left internal mammary artery (LIMA) grafting through an inferior J-hemisternotomy with percutaneous coronary intervention (PCI).
\end{abstract}

Methods: Prospective, single-arm clinical feasibility study including 100 consecutive patients with multivessel disease undergoing staged HCR. The primary endpoint was the major adverse cardiac and cerebrovascular event rate at 1 year. Secondary endpoints included 1-year all-cause death, stroke, myocardial infarction, repeat revascularization, and angiographic graft and stent patency.

Results: One-year clinical follow-up data were available in all patients. The primary endpoint was met by 20 patients $(20 \%)$. Individual endpoints were as follows: 1 death due to heart failure; 1 stroke, 2 procedure-related myocardial infarctions; and 1 spontaneous myocardial infarction during follow-up. A total of 16 patients underwent repeat revascularization: 5 surgical reinterventions during the index hospitalization for angiographically suspected internal mammary artery graft dysfunction, and 3 repeat PCIs. Only 1 patient had evidence of ischemia. After discharge, PCI was performed in 6 patients who had recurrent angina, and in 2 asymptomatic patients who had angiographic restenosis. At the 1-year angiographic follow-up, 87 of 89 (98\%) patients had patent internal mammary artery grafts. Angiographic restenosis was present in 10 of 100 lesions treated by PCI.

Conclusions: Angiographically controlled HCR was associated with a high repeat revascularization rate. The 1-year 98\% LIMA-graft patency rate, and low risk of death and stroke, seem promising for the long-term outcome. Non-left anterior descending coronary artery lesion revascularization remains a challenge. (J Thorac Cardiovasc Surg 2015;150:1181-6)

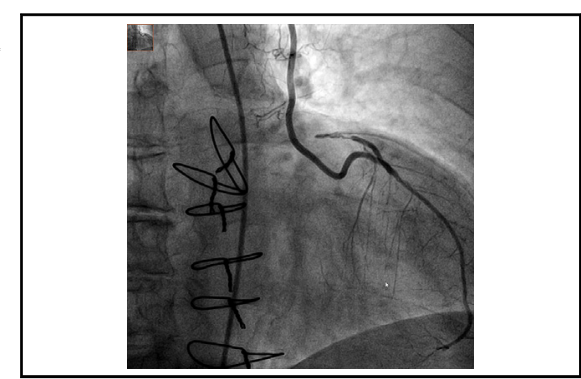

High left internal mammary artery graft patency seems promising for long-term survival after hybrid coronary revascularization.

\section{Central Message}

High 1-year LIMA graft patency, and low risk of death and stroke, seem promising for longterm outcome after HCR.

\section{Perspective}

Theoretically, HCR may increase survival and reduce the risk of stroke, compared with conventional revascularization. The high LIMA graft patency rate and low risk of death and stroke at 1 year seem promising for the longterm outcome of this revascularization strategy. Non-LAD revascularization remains a challenge.

See Editorial page 1028.
In patients with stable multivessel coronary artery disease involving the proximal left anterior descending coronary artery (LAD), current evidence indicates that coronary artery bypass grafting (CABG) should be advocated,

\footnotetext{
From the Departments of ${ }^{\mathrm{a} C}$ Cardiothoracic Surgery and ${ }^{\mathrm{b}}$ Cardiology, Aarhus University Hospital, Aarhus, Denmark.

Trial registration: ClinicalTrials.gov NCT01496664.

Received for publication May 8, 2015; revisions received June 17, 2015; accepted for publication Aug 15, 2015; available ahead of print Oct 1, 2015.

Address for reprints: Ivy S. Modrau, MD, DMSc, Department of Cardiothoracic

Surgery, Aarhus University Hospital, Palle Juul-Jensens Boulevard 99, 8200

Aarhus N, Denmark (E-mail: modrau@mail1.stofanet.dk).

$0022-5223 / \$ 36.00$

Copyright (c) 2015 by The American Association for Thoracic Surgery

http://dx.doi.org/10.1016/j.jtcvs.2015.08.072
}

rather than percutaneous coronary intervention (PCI). ${ }^{1,2}$ Undergoing $\mathrm{CABG}$ is associated with superior long-term survival, and a lower incidence of repeat revascularization, but at the same time, a temporarily increased risk of stroke. ${ }^{3-6}$ Substantial evidence indicates that having a graft from the left internal mammary artery (LIMA) to the LAD is the main determinant of a favorable outcome of CABG. ${ }^{7-9}$ The benefit of other conduits to non-LAD vessels remains less clear, and surgical revascularization of non-LAD territories is challenged by PCI in which new generations of drug-eluting stents are used, with low rates of early and late major adverse cardiac events. ${ }^{10,11}$

The rationale of hybrid coronary revascularization (HCR) is to achieve the survival benefits of the LIMA-to-LAD graft 


\section{Abbreviations and Acronyms \\ $\mathrm{CABG}=$ coronary artery bypass grafting \\ EuroSCORE $=$ European System for Cardiac \\ Operative Risk Evaluation

$\begin{array}{ll}\text { HCR } & \text { hybrid coronary revascularization } \\ \text { LAD } & \text { left anterior descending coronary } \\ & \text { artery } \\ \text { LIMA } & \text { left internal mammary artery } \\ \text { MACCE }= & \text { major adverse cardiac and } \\ & \text { cerebrovascular events } \\ \text { PCI } & =\text { percutaneous coronary intervention } \\ \text { SYNTAX } & \text { synergy between PCI with Taxus and } \\ & \text { cardiac surgery }\end{array}$

with reduced invasiveness to minimize postprocedural discomfort and morbidity, particularly the risk of stroke. Although the incidence of stroke has decreased over the past few decades, it is still more frequent in the year immediately after CABG than after PCI. ${ }^{6,12}$

During the past 2 decades, the concept of HCR has been assessed in numerous case series and registry studies, mainly retrospective and including selected patients. ${ }^{13}$ Most studies on HCR applied minimally invasive direct CABG, performing the LIMA-to-LAD graft off-pump through an anterolateral mini-thoracotomy. Most of the initial series harvested the LIMA under direct vision, whereas recent series used thoracoscopic or robotic techniques. Few studies used totally endoscopic CABG, a closed-chest robotic approach, either off or on pump. Alternatively, the LIMA-to-LAD graft may be performed as an off-pump procedure through an inferior reversed J-hemisternotomy. We chose this technique because of its excellent exposure of the heart, technical ease, low risk of complicating chronic pain, and applicability in virtually all patients. ${ }^{14}$ Consecutive series of elective HCR with well-defined criteria of inclusion, and systematic clinical and angiographic follow-up, are scarce.

\section{METHODS \\ Study Design}

We performed a prospective, single-arm, single-center clinical feasibility study on elective, staged HCR, combining LIMA-to-LAD grafting, performed as an off-pump procedure through an inferior reversed J-hemisternotomy, with PCI. This prespecified analysis presents the 1-year clinical and angiographic outcomes of 100 patients with multivessel disease.

The local heart team, consisting of interventional cardiologists and cardiac surgeons, evaluated all patients referred to Aarhus University Hospital in Denmark for coronary revascularization. Inclusion criteria were as follows: significant stenosis $(>75 \%$ by visual assessment, or fractional flow reserve $<80 \%$ ) or occlusion of the proximal LAD; a LAD amenable to surgical revascularization; and $\leq 3$ non-LAD lesions suitable for PCI. Per protocol, we limited the number of non-LAD lesions as a means to minimize the complexity of the PCI procedure. In asymptomatic patients, documentation of myocardial ischemia was required. Exclusion criteria were as follows: need of complex stenting (defined as stenting of a bifurcation lesion or excessive tortuosity of proximal segment; extremely angulated segments [ $\left.>90^{\circ}\right]$, and severely tortuous and/or calcified coronary lesion); ST-elevation myocardial infarction within 24 hours; expected survival of $<1$ year; history of CABG or PCI with use of drug-eluting stents; and contraindication to double antiplatelet treatment or drug-eluting stents.

Surgery was scheduled to precede PCI by 2 to 5 days. In the case of chronically occluded non-LAD vessels, PCI was performed 2 days prior to surgery to avoid surgical reintervention in case of PCI failure. Written informed consent was obtained from all participants. The study conformed to the principles outlined in the Declaration of Helsinki and was approved by the Central Denmark Region Committees on Biomedical Research Ethics.

\section{Surgical Technique and Perioperative Management}

A CABG procedure was performed as an off-pump LIMA-to-LAD anastomosis through an inferior reversed J-hemisternotomy up to the left third or fourth intercostal space. The LIMA was harvested up to the sternal transection under direct vision, using a modified mammary retractor. Unfractionated heparin $300 \mathrm{IU} / \mathrm{kg}$ was administered during harvest of the LIMA, and additional boluses were given as required to maintain an activated clotting time of $>400$ seconds. Following a C-formed incision of the pericardium, left-sided pericardial stay sutures were placed to expose the LAD. Standard off-pump revascularization of the anterior wall was performed as described elsewhere. ${ }^{15}$ Briefly, the LAD was snared proximal to the anastomosis site, while an intracoronary shunt was inserted. Anastomosis between LIMA and LAD was performed with a running monophilic suture under direct vision using a suction stabilizer and a small sternal retractor. At the end of the procedure, the anticoagulation effect of heparin was antagonized with protamine at a ratio of $1: 1$ to the initial dose of heparin. Patients who had stopped acetylsalicylic acid therapy prior to surgery resumed the treatment with a bolus of $300 \mathrm{mg}$ orally, 6 to 9 hours postoperatively.

From day 1 after surgery, all patients received a lifelong daily maintenance dose of $75 \mathrm{mg}$ of acetylsalicylic acid. In patients who had surgery prior to PCI, subcutaneous dalteparin 5000 IE was given twice daily until the day before PCI, to prevent deep venous thrombosis. Patients on dual antiplatelet therapy after PCI and before the off-pump CABG with inferior reversed J-hemisternotomy did not receive low molecular heparin therapy postoperatively. After hemisternotomy, no physical restrictions were imposed other than to respect the individual's pain threshold.

\section{Percutaneous Coronary Intervention}

All patients received a loading dose of clopidogrel $(300 \mathrm{mg})$ on the evening immediately preceding PCI. For those who underwent off-pump CABG with inferior reversed J-hemisternotomy prior to PCI, angiographic assessment of the LIMA graft was conducted. Before stenting, the patients received unfractionated heparin (70-100 IU/kg body weight) intravenously, to achieve an activated clotting time of $>250$ seconds. Borderline stenoses were assessed by fractional flow reserve measurement. Standard best practices were used to perform PCI with second- and third-generation drug-eluting stents. After PCI, all patients received a daily maintenance dose of $75 \mathrm{mg}$ of clopidogrel for 1 year, in addition to acetylsalicylic acid.

\section{Definitions and Follow-up}

The primary endpoint was the rate of major adverse cardiac or cerebrovascular events (MACCE), the composite of all-cause death, stroke, myocardial infarction, and repeat revascularization by PCI or CABG at 1 year. Secondary endpoints included the individual components and angiographic graft and stent patency. 
TABLE 1. Baseline characteristics and risk assessment scores of $\mathbf{1 0 0}$ patients scheduled for hybrid coronary revascularization

\begin{tabular}{lc}
\hline \multicolumn{1}{c}{ Characteristic } & Value \\
\hline Age $(\mathrm{y})$ & $69(43-87)$ \\
Gender, male & 76 \\
Body mass index $\left(\mathrm{kg} / \mathrm{m}^{2}\right)$ & $27(21-47)$ \\
Indication & \\
$\quad$ Silent ischemia & 3 \\
$\quad$ Stable angina pectoris & 58 \\
$\quad$ Acute coronary syndrome & 39 \\
Family history of coronary artery disease & 55 \\
Arterial hypertension & 72 \\
Hypercholesterolemia & 85 \\
Current smoker & 18 \\
Diabetes mellitus & 22 \\
EuroSCORE I $(\%)$ & $2.1(0.9-30.7)$ \\
SYNTAX score & $13(4-26.5)$ \\
Non-LAD SYNTAX score & $5(0-5)$ \\
Ejection fraction $(\%)$ & $60(25-70)$ \\
\hline
\end{tabular}

Figures are given as $\%$, or absolute number (\%), or median (range). The logistic EuroSCORE reflects higher predicted mortality with higher values. ${ }^{19}$ The SYNTAX score provides a comprehensive assessment of coronary pathology; higher scores indicate more-complex coronary disease. ${ }^{18}$ EuroSCORE, European system for cardiac operative risk evaluation; SYNTAX, synergy between percutaneous coronary intervention with Taxus and cardiac surgery; $L A D$, left anterior descending coronary artery.

Myocardial infarction was defined according to the Task Force for the Redefinition of Myocardial Infarction. ${ }^{16}$ Stroke was defined as a focal or central neurologic deficit lasting $>24$ hours, and repeat revascularization as any surgical or catheter-based target lesion intervention after the index procedures.

At 1-year follow-up angiography, LIMA grafts and vessels treated by PCI were evaluated by independent professionals at the angiographic core laboratory at Aarhus University Hospital, Skejby, Aarhus, Denmark. The LIMA grafts were scored visually according to the FitzGibbon AB0 classification. ${ }^{17}$ The FitzGibbon $\mathrm{A}$ is an excellent graft with unimpaired run-off; B is an impaired graft with a stenosis that reduces the caliber of the graft at any site to $<50 \%$ of the grafted coronary artery diameter; and $\mathrm{O}$ is an occluded graft. Grafts with a "string sign" with reduced flow were classified as FitzGibbon B. Vessels treated with a stent were assessed by quantitative coronary analysis, using a dedicated computer-based system (QAngio XA, version 7.3; Medis, Leiden, The Netherlands). Index lesions were defined as the stented part of the vessel, including $5 \mathrm{~mm}$ before and after the stent, and angiographic restenosis $\geq 50 \%$ diameter stenosis.

The SYNTAX (synergy between PCI with Taxus and cardiac surgery) score was calculated for all patients. ${ }^{18}$ In addition, we calculated a "non-LAD"-SYNTAX score to describe the complexity of the lesion(s) left to be treated by PCI. The European System for Cardiac Operative Risk Evaluation (logistic EuroSCORE I) was calculated in all patients to predict perioperative mortality. ${ }^{19}$

\section{Data Management and Statistics}

All data were prospectively entered in EpiData Entry (The EpiData Association, Odense, Denmark), applying double entry verification for data quality control. Binary variables were presented as counts and percentages. Continuous variables were reported as median and range.

\section{RESULTS}

Between October 2010 and February 2012, a total of 100 consecutive patients with multivessel disease were prospectively enrolled in our study. Baseline characteristics and preoperatively calculated risk assessment scores are reported in Table 1. A CABG off-pump procedure, with inferior reversed J-hemisternotomy, was performed prior to $\mathrm{PCI}$ in 89 patients $(89 \%)$; PCI was performed prior to surgery in 11 patients $(11 \%)$ who had total occlusion of a non-LAD. Procedural feasibility and 1-month safety results have been published. ${ }^{14}$

Clinical follow-up at 1 year was available for all patients. The 1-year endpoint of MACCE was met by 20 patients $(20 \%)$. One death occurred $(1 \%)$, as well as $1(1 \%)$ stroke, and $3(3 \%)$ myocardial infarctions. Sixteen patients underwent repeat revascularization $(16 \%)$. The fatality was caused by heart failure after 7 months (preoperative logistic EuroSCORE I: $11.6 \%$ ); the case of stroke occurred postoperatively at day 4 . Two of the myocardial infarctions were procedure related, 1 coming after off-pump CABG with inferior reversed J-hemisternotomy, with LIMA graft occlusion, and 1 coming after PCI.

Of 16 patients who underwent repeat revascularization, 8 of the procedures were performed during the index hospitalization. Five patients underwent surgical reintervention due to LIMA graft dysfunction (2 stenoses, 3 occluded grafts). Two occlusions were due to LIMA graft entrapment by the hemisternotomy closure, a pitfall that occurred during the early phase of the study. One patient who had significant anastomotic stenosis, but without flow limitation at angiography, showed a pulsatility index $<5$ by transit-time flow assessment at the time of reintervention. Three patients had a repeat PCI (failed index PCI in 2 patients; PCI of the LAD in 1 patient who had a LIMA-to-diagonal graft). Only 1 of these 8 patients had evidence of ischemia - the patient with an occluded LIMA graft who had perioperative myocardial infarction. In that case, the reoperation was a conventional CABG, as the LAD had shown marked arteriosclerotic disease during the off-pump $\mathrm{CAB}$ procedure with inferior reversed J-hemisternotomy. All 8 patients were discharged, having undergone successful revascularization, in a state of well-being, without deterioration of ejection fraction at discharge. At 1-year follow-up, all 5 LIMA grafts revised in-hospital were patent.

After discharge, repeat revascularization was performed in 8 patients. Of these, repeat revascularization was driven by recurrent angina or equivalents in 5 patients, and 1 was caused by unstable angina, owing to an occluded LIMA graft. The remaining 2 patients were asymptomatic and were treated using PCI, based on findings at the prescheduled angiography. One of these patients had repeat non-target-lesion PCI during the follow-up period.

Prescheduled coronary angiography at 1-year follow-up was available in $89(89 \%)$ patients. Patients with in-hospital reinterventions $(\mathrm{n}=8)$ were not censored for 1-year angiographic follow-up. The LIMA grafts were 
found to be patent in 87 of $89(98 \%)$ patients. According to the FitzGibbon grades of graft patency, 75 of $89(84 \%)$ LIMA grafts were classified as grade A; 12 of $89(13 \%)$ as grade $\mathrm{B}$; and 2 of $89(2 \%)$ grafts as grade 0 . Angiographic restenosis $(\geq 50 \%$ diameter stenosis $)$ of PCI-treated index lesions was found in 10 of $100(10 \%)$ analyzed lesions in 89 patients. Two of the target lesion failures were total occlusions.

\section{DISCUSSION}

This prospective clinical feasibility study on HCR with 1-year clinical and angiographic follow-up, showed a high rate of MACCE, driven predominantly by the high rate of repeat revascularization. However, half of the repeat revascularizations were performed in-hospital. All patients had undergone successful revascularization at discharge. We observed a low total risk of death $(1 \%)$ and stroke $(1 \%)$ at 1-year follow-up. When LIMA patency was angiographically controlled and repaired, in case of early dysfunction, patency was high after 1 year $(98 \%)$. These findings seem promising for the long-term outcome after HCR, but extrapolation of results is limited by the high rate of reinterventions driven by angiography.

Well-powered randomized studies, and large-scale registries in patients with stable multivessel disease, have documented the superiority of CABG compared with PCI, taking into consideration repeat revascularization, myocardial infarction, and death, whereas early stroke rates were increased after surgical revascularization., ${ }^{4,20,21}$ Consequently, international guidelines recommend CABG as the first-line treatment in patients with stable multivessel disease. ${ }^{1,2}$ In clinical practice, patients with multivessel disease are referred to PCI more often than anticipated by guidelines. ${ }^{22}$ However, the choice of a less-invasive therapy may be the result of active patient participation in the decision-making process, rather than lack of adherence to evidence-based recommendations. ${ }^{2}$ The aim with HCR is to achieve the survival benefits of the LIMA-to-LAD graft but with reduced invasiveness, to minimize postprocedural discomfort and morbidity, in particular the risk of stroke.

The MACCE rate of $20 \%$ in our study was higher than expected and does not compare favorably with the 1-year SYNTAX Study MACCE rates $(17.8 \%$ in the PCI and $12.4 \%$ in the CABG group). ${ }^{12}$ However, our MACCE rate was driven largely by 16 repeat revascularizations. Half of the repeat revascularizations were undertaken during the index hospitalization. Only 1 of these patients had shown clinical evidence of ischemia. The number of in-hospital repeat revascularizations exceeded the rate of $<1 \%$ after conventional $\mathrm{CABG}$ at our institution. Part of the LIMA-related problems might be related to the learning curve in our feasibility study. However, prior studies with systematic early angiography have shown similar rates of LIMA graft stenosis and occlusion after conventional on-pump CABG. ${ }^{23,24}$ Thus, early angiography may unveil clinically silent LIMA graft dysfunction due to technical errors.

In our study, all 8 patients were considered successfully revascularized at discharge. At 1-year follow-up, all 5 LIMA grafts revised in-hospital were patent. Angiographic evaluation of LIMA grafts in the early postoperative phase is challenging, as most significant stenoses in both the trunk and at the distal anastomosis may not be visualized on follow-up. ${ }^{25}$ Consequently, reintervention probably should be performed only in the presence of clinical signs of ischemia and/or angiographic flow limitation.

The number of clinically driven repeat revascularizations at 1-year follow-up was 7\% (1 patient in-hospital, 6 patients after discharge). This percentage is in line with the SYNTAX Study, in which $6 \%$ of patients in the CABG-group required repeat revascularization at 1 year. ${ }^{12}$ However, a contemporary meta-analysis of 6 observational studies, including 1190 patients comparing HCR to CABG disclosed a lower rate of repeat revascularization at 1-year follow-up (3.8\% after HCR vs $1.4 \%$ after CABG). ${ }^{26}$

We observed a low risk of death $(1 \%)$ and stroke $(1 \%)$ at 1 year. These promising results are comparable with the 1 -year clinical outcomes published in the meta-analysis by Harskamp and colleagues. ${ }^{26}$ They reported all-cause mortality at 1 year of $1.7 \%$ after HCR, compared with $4.1 \%$ after CABG. The stroke rate at 1-year follow-up was zero after HCR, compared with $2.4 \%$ after CABG. Recently, feasibility of HCR was demonstrated in the first randomized controlled trial comparing $\mathrm{HCR}$ and $\mathrm{CABG}$ in 200 patients. ${ }^{27}$ In this study, HCR was performed as a staged procedure with minimally invasive direct coronary artery bypass, followed by PCI within 36 hours. After 1 year, survival was similar in the HCR and CABG groups (98\% vs $97 \%$ ), and no strokes had occurred.

Recent final analyses of adverse events in the SYNTAX subgroup of patients with 3-vessel disease showed no difference between CABG and PCI regarding the endpoint of stroke after 5 years of follow-up. ${ }^{28}$ Most strokes that occurred after PCI were in patients with complex coronary lesions (SYNTAX score $\geq 33$ ). However, the small sample size of approximately 500 patients in both groups implies insufficient power for a low-frequency event such as stroke. A point of continuing speculation is whether the convergence of stroke rates over time is attributable to more-rigorous lifestyle modification after $\mathrm{CABG}$, to the more frequently repeated revascularizations after PCI, or is random. In a recent meta-analysis of randomized controlled trials comparing CABG with PCI, and including $>15,000$ patients with multivessel disease, outcomes were assessed at the maximum available follow-up. ${ }^{6}$ The analysis demonstrated that $\mathrm{CABG}$ was associated with a lower risk of death, a lower risk of repeat revascularization, but an increased risk of stroke. 
The ultimate assessment of safety and efficacy of HCR will necessitate long-term clinical follow-up data and head-to-head comparison, in randomized controlled trials, of these data with those for the conventional treatment modalities of CABG and PCI. Meanwhile, LIMA patency, the cornerstone of surgical revascularization, may be used as a surrogate endpoint for long-term survival after HCR. Thus, the high LIMA patency rate of $98 \%$ at 1 -year follow-up seems promising for the long-term outcome after HCR.

Our study has limitations. The major drawback of a prospective clinical feasibility study is the lack of a control group. Classification according to EuroSCORE I and SYNTAX scores indicates a relatively low-risk profile of the patients enrolled in our study. It is a consequence of the exclusion of $>3$ or complex coronary lesions. With due regard to the current guidelines, this subset of patients with a SYNTAX score $\leq 22$, and low predicted surgical mortality, will be offered multivessel PCI at many institutions. Furthermore, our results represent findings at a single academic hospital and may not be generalizable.

In conclusion, this prospective clinical feasibility study of HCR showed a high rate of MACCE at 1-year followup, partly due to angiographically driven revascularization. The high out-of-hospital LIMA patency rate and low risk of death and stroke seem promising for the long-term outcome after HCR. Non-LAD lesion revascularization remains a challenge.

\section{Conflict of Interest Statement}

Authors have nothing to disclose with regard to commercial support.

The authors thank research nurse Vibeke Laursen, secretary Helle Bargsteen, and research coordinators Pia Stycke Ottosen and Lars Peter Jørgensen for their invaluable support. We thank members of the Hybrid Coronary Revascularization Study Group, from Aarhus University Hospital (Aarhus, Denmark), Department of Cardiothoracic Surgery: Vibeke E. Hjortdal, MD, PhD, DMSc, and Department of Cardiology: Christian Juhl Terkelsen, MD, DMSc, PhD, Anne Kjer Kaltoft, MD, PhD, Lars Romer Krusell, MD, Henning Skov Kelbæk, MD, DMSc, and Lone Kærslund Andersen, MD.

\section{References}

1. Hillis LD, Smith PK, Anderson JL, Bittl JA, Bridges CR, Byrne JG, et al. 2011 ACCF/AHA Guideline for Coronary Artery Bypass Graft Surgery: executive summary. J Am Coll Cardiol. 2011;58:2584-614.

2. Kolh P, Windecker S, Alfonso F, Collet JP, Cremer J, Falk V, et al. 2014 ESC/ EACTS Guidelines on myocardial revascularization: The Task Force on Myocardial Revascularization of the European Society of Cardiology (ESC) and the European Association for Cardio-Thoracic Surgery (EACTS). Eur J Cardiothorac Surg. 2014;46:517-92.

3. Mohr FW, Morice M-C, Kappetein AP, Feldman TE, Ståhle E, Colombo A, et al. Coronary artery bypass graft surgery versus percutaneous coronary intervention in patients with three-vessel disease and left main coronary disease: 5-year follow-up of the randomised, clinical SYNTAX trial. Lancet 2013:381:629-38.

4. Farkouh ME, Domanski M, Sleeper LA, Siami FS, Dangas G, Mack MJ, et al Strategies for multivessel revascularization in patients with diabetes. $N$ Engl J Med. 2012;367:2375-84.

5. Weintraub WS, Weiss JM, Peterson ED, Klein LW, Ritzenthaler LL, Shahian DM, et al. Comparative effectiveness of revascularization strategies. N Engl J Med. 2012;367:476-7.

6. Smit Y, Vlayen J, Koppenaal H, Eefting F, Kappetein AP, Mariani MA Percutaneous coronary intvervention versus coronary artery bypass grafting: a meta-analysis. J Thorac Cardiovasc Surg. 2015;149:831-8.

7. Cameron A, Davis KB, Green G, Schaff HV. Coronary bypass surgery with internal-thoracic-artery grafts-effects on survival over a 15 -year period. $N$ Engl J Med. 1996;334:216-9.

8. Loop FD, Lytle BW, Cosgrove DM, Stewart RW, Goormastic M, Williams GW, et al. Influence of the internal-mammary-artery graft on 10-year survival and other cardiac events. New Engl J Med. 1986;314:1-6.

9. Benedetto U, Raja S, Soliman R, Albanese A, Jothidasan A, Ilsley C, et al Minimally invasive direct coronary artery bypass improves late survival compared with drug-eluting stents in isolated proximal left anterior descending artery disease: a 10-year follow-up, single-center, propensity score analysis. $J$ Thorac Cardiovasc Surg. 2014;148:1316-22.

10. Greenhalgh J, Hockenhull J, Rao N, Dundar Y, Dickson RC, Bagust A Drug-eluting stents versus bare metal stents for angina or acute coronary syndromes. Cochrane Database Syst Rev. 2010;5:CD004587.

11. Jensen LO, Thayssen P, Maeng M, Christiansen EH, Ravkilde J, Hansen KN et al. Three-year outcomes after revascularization with everolimus- and sirolimus-eluting stents from the SORT OUT IV trial. J Am Coll Cardiol Card Interv. 2014;7:840-8.

12. Serruys PW, Morice MC, Kappetein AP, Colombo A, Holmes DR, Mack MJ et al. Percutaneous coronary intervention versus coronary-artery bypass grafting for severe coronary artery disease. New Engl J Med. 2009;360: 961-72.

13. Verhaegh AJ, Accord RE, van Garsse L, Maessen JG. Hybrid coronary revascularization as a safe, feasible, and viable alternative to conventional coronary artery bypass grafting: What is the current evidence? Minim Invasive Surg. 2013;2013:142616.

14. Modrau IS, Nielsen PH, Bøtker HE, Christiansen EH, Krusell LR, Kaltoft AK et al. Feasibility and early safety of hybrid coronary revascularisation combining off-pump coronary surgery through J-hemisternotomy with percutaneous coronary intervention. EuroIntervention. 2015;10:e1-6.

15. De Raet JM, DeSimone JP, Sergeant PT. Off-pump coronary artery bypass grafting: anno 2011. Multimed Man Cardiothorac Surg. 2011;2011:713.

16. Thygesen K, Alpert JS, White HD. Universal definition of myocardial infarction. Eur Heart J. 2007;28:2525-38.

17. FitzGibbon GM, Burton JR, Leach AJ. Coronary bypass graft fate: angiographic grading of 1400 consecutive grafts early after operation and of 1132 after one year. Circulation. 1978;57:1070-4.

18. Sianos G, Morel MA, Kappetein AP, Morice MC, Colombo A, Dawkins K, et al The SYNTAX Score: an angiographic tool grading the complexity of coronary artery disease. EuroIntervention. 2005;1:219-27.

19. Nashef SA, Roques F, Michel P, Gauducheau E, Lemeshow S, Salamon R European system for cardiac operative risk evaluation (EuroSCORE). Eur $J$ Cardiothorac Surg. 1999;16:9-13.

20. Hannan EL, Wu C, Walford G, Culliford AT, Gold JP, Smith CR, et al Drug-eluting stents vs. coronary-artery bypass grafting in multivessel coronary disease. N Engl J Med. 2008;358:331-41.

21. Weintraub WS, Grau-Sepulveda MV, Weiss JM, O'Brien SM, Peterson ED Kolm P, et al. Comparative effectiveness of revascularization strategies. $N$ Engl J Med. 2012;366:1467-76.

22. Hannan EL, Racz MJ, Gold J, Cozzens K, Stamato NJ, Powell T, et al. Adherence of catheterization laboratory cardiologists to American College of Cardiology/ American Heart Association guidelines for percutaneous coronary interventions and coronary artery bypass graft surgery: What happens in actual practice? Circulation. 2010;121:267-75.

23. Berger PB, Alderman EL, Nadel A, Schaff HV. Median sternotomy on conventional bypass: benchmark for minimally to left anterior descending artery bypass graft after surgery through a frequency of early occlusion and stenosis in a left internal mammary artery invasive direct coronary artery bypass. Circulation. 1999;100:2353-8. 
24. Zhao DX, Leacche M, Balaguer JM, Boudoulas KD, Damp JA, Greelish JP, et al. Routine intraoperative completion angiography after coronary artery bypass grafting and 1-stop hybrid revascularization results from a fully integrated hybrid catheterization laboratory/operating room. J Am Coll Cardiol. 2009;53: 232-41.

25. Wiklund L, Johansson M, Brandrup-Wognsen G, Bugge M, Rådberg G, Berglin E. Difficulties in the interpretation of coronary angiogram early after coronary artery bypass surgery on the beating heart. Eur J Cardiothorac Surg. 2000;17:46-51.

26. Harskamp RE, Bagai A, Halkos ME, Rao SV, Bachinsky WB, Patel MR, et al. Clinical outcomes after hybrid coronary revascularization versus coronary artery bypass surgery: a meta-analysis of 1,190 patients. Am Heart J. 2014; 167:585-92.
27. Gąsior M, Zembala MO, Tajstra M, Filipiak K, Gierlotka M, Hrapkowicz T, et al. Hybrid revascularization for multivessel coronary artery disease. J Am Coll Cardiol Interv. 2014;7:1277-83.

28. Head SJ, Davierwala PM, Serruys PW, Redwood SR, Colombo A, Mack MJ, et al. Coronary artery bypass grafting vs. percutaneous coronary intervention for patients with three-vessel disease: final five-year follow-up of the SYNTAX trial. Eur Heart J. 2014;35:2821-30.

Key Words: hybrid coronary revascularization, coronary revascularization, coronary artery bypass grafting, percutaneous coronary intervention

Readers who found these articles interesting may also like to read the following papers found in recent and future issues of our sister publications, Seminars in Thoracic and Cardiovascular Surgery and Operative Techniques in Thoracic and Cardiovascular Surgery!

\section{Acquired Cardiovascular Disease: Coronary Artery Disease}

News and Views: Outcomes of Arterial Revascularization. Stephen Fremes. Semin Thorac Cardiovasc Surg 2014; Autumn; 26(3): 174-175.

News and Views: Editorial on Multiple Arterial Grafting. Brian Buxton. Semin Thorac Cardiovasc Surg 2014; Autumn; 26(3): 176-178.

News and Views: Role of PCI in the Treatment of Left Main Coronary Disease. A. P. Kappetein. Semin Thorac Cardiovasc Surg 2014; Autumn; 26(3):187-191.

State of the Art: Use of Anti-platelet Drugs after Cardiac Operations. Victor Ferraris. Semin Thorac Cardiovasc Surg 2014; Autumn; 26(3):223-230. 